Ambient Science, 2019: Vol. 06(Sp1); 43-44

DOI:10.21276/ambi.2019.06.sp1.nn03

\title{
HIV Treatment: Towards Bioactive Compounds of plant origin
}

\section{Simran Dawar, Pratik Chawla, Arshdeep Singh , Rajesh Ghangal*}

Department of Biotechnology, Manav Rachna International Institute of Research Studies, Sector-43, Surajkund Road, Faridabad, Haryana, India

\section{Introduction:}

The year 1983 saw the detection of one of the most deadly and malicious viruses, known as the Human Immunodeficiency Virus (HIV). Following the report of World Health Organisation, over 36.9 million people had HIV at the end of 2017, all over the world (Deeks et al., 2015, WHO http://www.who.int/hiv/data/epi_plhiv_ 2016_regions.png?ua=1) Over 1.8 million people were newly infected in 2017, out of which 59\% were adult and 52\% were children. In South Africa it was estimated that over $18.9 \%$ of adults had HIV in 2016, however, in Botswana there were 21.9\% of adults having HIV infection (WHO et al., 2017). In Lesotho there were $25 \%$ of adults having HIV infection. Fortunately, in India, there was a reduction in HIV patients. It is recorded that there were 0.274 million HIV patients in 2000 but this number reduced to 0.116 million in the year 2011. According to the data obtained in 2016, there were approximately 2 million new cases of HIV infection recorded globally and approximately one million people died of the infection (WHO et al., 2017).

Scientists have been researching from time immoral to find suitable medicinal plants that would act as anti-HIV. There are some plants that could be used to cure HIV/AIDS. For example, Agastache rugosa/ Lamiaceae contain compounds like Arastanol and Agastaquinone. These compounds play an important role as they are protease inhibitors (Min et al.,1999). Alpinia rugosa / Zingiberaceae contain 1'S-1' -acetoxychavicol which plays a crucial role against HIV as it has anti-HIV activity. There are many more plants like Acer okamotoanum, Arnebia euchroma, members of Labiateae, Clusiaceae, Ginkgoaceae, Dipterocarpaceae, etc. whose anti- HIV activity has been discovered. These plants contain some compounds which are responsible for these activities.

\section{Pathophysiology:}

HIV virus integrates the viral genome DNA, into host cell DNA. The receptors present on monocytes, dendritic cells, $\mathrm{T}$ lymphocytes, and macrophages are responsible for the entry of the virus into the cell (Deeks et al., 2015). The
Key words: Human immunodeficiency virus, Antiretroviral therapies, Reverse transcriptase retrovirus, HIV attaches to the chemokine receptor 5 or CXC chemokine receptor 4 presents on monocytes, dendritic cells, macrophages, and T lymphocytes. After entering the cell, RNA through reverse transcription becomes HIV DNA and is then incorporated into the host genome. Then it replicates over and over till the cell is present. This is why it is very tough to get rid of HIV fully. The genome now undergoes transcription and forms viral mRNA which is transferred to the cytoplasm and the mRNA translates into Gag-Pol, viral Gag, and Nefpolyproteins and are cleaved during the final step of the cycle i.e. the formation of virus particles, their assembly, maturation and thus release of new virions takes place. The therapies inhibit either of the one stages of this cycle i.e. either inhibit the entry, reverse transcription, integration or transfer, etc.

\section{Current treatment for HIV:}

Since HIV identified, till there is no medicine or vaccines to cure it completely. In 1996, many antiretroviral therapies had been introduced which led to a significant decrease in the mortality of HIV and AIDS. Protease inhibition therapy is not committed (Auvert et al., 2005; Bailey et al., 2007; Anderson et al., 2014). Due to the introduction of new therapies, HIV became a chronic and manageable disease from a fatal one. The survival rate has been increasing due to the introduction of highly active antiretroviral therapies. Scientists are finding new ways to cure HIV by developing new vaccines, antimicrobial agents, etc. (Anderson et al., 2014; Maartens et al., 2014). There are various substitutes available nowadays such as histone deacetylase (HDAC) inhibitors, anti-HIV antibodies, immune modulation and gene therapies which are considered to be a better alternative for antiretroviral therapy (ART) (Bailey et al., 2007, Anderson et al., 2014, Kharsany et al., 2016).

\section{Plant extracts and secondary metabolites:}

Since the prehistoric period, several parts of the plants are used as medicine. Plants naturally fights against fungal, bacterial and viral attacks. Many plants produce secondary metabolites like phenolics, glycosides, alkaloids, essential oils and peptides (Sharifi et al., 2016, Lucera et al., 2014).

*Corresponding Author: rajeshghangal.fet@mriu.edu.in 
These secondary metabolites have many biological activities and some of them also help in increasing antiviral immunity. Since antiretroviral therapies have many side effects such as liver infection, etc so, scientists are focusing on plants to cure HIV (WHO et al., 1989, 1989, Kurapati et al., 2016). During the course of finding a cure for HIV, excess of mind storming was done and this led to many new significant and beneficial discoveries. One such discovery is the identification of the anti-HIV activity of Ecliptaprostrata. Although this plant is known to cure blood diseases and has been used for this purpose by the doctors in Thai, its anti-HIV property was first recorded by the bioassay technique. The six compounds identified were -5-hydroxymethyl-(2,2':5',2')-terthienyltiglate, 5hydroxymethyl- $\left(2,2^{\prime}: 5^{\prime}, 2^{\prime \prime}\right)$-terthienylagelate, 5hydroxymethyl-(2,2':5',2")-terthienyl acetate, ecliptal , orobol and wedelolactone. Out of all of them, wedelolactone showed highest activity against HIV-1 Integrase (IN) and had 4.0+-0.2 $\mathrm{UM} \mathrm{IC}_{50}$ value and orobol had $\mathrm{IC}_{50}$ value of 8.1+-0.5 UM whereas the other four compounds were inactive and had $\mathrm{Ic}_{50}>_{100} \mathrm{UM}$. In terms of HIV-1 protease inhibitory activity, 5-hydroxymethyl$\left(2,2^{\prime}: 5^{\prime}, 2^{\prime \prime}\right)$-terthienyltiglate had highest activity. HIV-1 PR

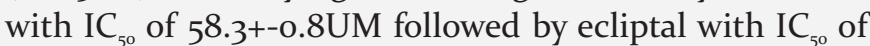
83.3+-1.6UM and IC50 of 93.7+--0.8UM of 5-hydroxymethyl$\left(2,2^{\prime}: 5^{\prime}, 2^{\prime \prime}\right)$-terthienyl acetate meanwhile 5-hydroxymethyl$\left(2,2^{\prime}: 5^{\prime}, 2^{\prime \prime}\right)$-terthienylagelate, orobol and wedelolactone were inactive and had $\mathrm{Ic}_{50}>{ }_{100} \mathrm{UM}$. (Tewtrakul et al., 2007).

So, there is a need to develop plant-based medicines or vaccines in order to reduce the side effects. The use of secondary metabolites to fight with HIV is one of the important steps (Guay et al., 1999). The extracts of medicinal plants have been reviewed, which have shown to possess anti-HIV activities and some of these medicinal plants are - Artemisia annua, Astragalus membranaceus, Calendula officinalis, Chelidonium majus, Combretum molle, Diospyros lotus, Dittrichia viscosa, Galanthus nivalis, Garcinia edulis, , Hoodia gordonii, Hypericum perforatum, Hyssopus officinalis, Justicia gendarussa, Momordica charantia, Pachyma hoelen, Phyllanthus pulcher, Rhus chinensis, Sceletium tortuosum, Smilax corbularia, Terminalia paniculata and Tuberaria lignosa.

\section{Conclusion:}

With the advancement in the techniques developed for curing HIV, there is an important need for natural methods. Several medicinal plants have been identified which are proven to have anti-HIV properties and can be seen as a potential cure for HIV. Thus, medicinal plants can be switched over the other antiretroviral therapies. Natural alternatives have less side effects as compared to ART.

\section{References:}

Anderson, S.J., Cherutich, P., Kilonzo, N., Cremin, I., Fecht, D., Kimanga, D., Harper, M., Masha, R.L., Ngongo, P.B., Maina,
W., Dybul, M. \& Hallett, T.B. (2014): Maximising the effect of combination HIV prevention through prioritisation of the people and places in greatest need: A modelling study. Lancet, 384(9939):249-256.

Auvert, B., Taljaard, D., Lagarde, E., Sobngwi-Tambekou, J., Sitta, R.\&Puren, A. (2005): Randomized, controlled intervention trial of male circumcision for reduction of HIV infection risk: TheANRS 1265 trial. PLoS Med., 2(11):e298.

Bailey, R.C., Moses, S., Parker, C.B., Agot, K., Maclean, I., Krieger, J.N., Williams, C.F., Campbell, R.T. \& Ndinya-Achola, J.O. (2007): Male circumcision for HIV prevention in young men in Kisumu, Kenya: A randomised controlled trial. Lancet, 369(9562):643-656.

Deeks, S.G., Overbaugh, J., Phillips, A. \& Buchbinder, S. (2015): HIV infection. Nat. Rev. Dis. Prim., 1:15035.

Deeks, S.G., Overbaugh, J., Phillips, A. \& Buchbinder, S. (2015): HIV infection. Nat. Rev. Dis. Prim, 1:15035

Guay, L.A., Musoke, P., Fleming, T.,Bagenda, D., Allen, M. Nakabiito, C., Sherman, J., Bakaki, P.,Ducar, C. \&Deseyve, M., Emel, L., Mirochnick, M., Fowler, M.G., Mofenson, L., Miotti,.P, Dransfield, K., Bray, D., Mmiro, F. \& Jackson, J.B..(1999): Intrapartum and neonatal single-dose nevirapine compared with zidovudine for prevention of mother-to-child transmission of HIV-1 in Kampala, Uganda: HIVNET 012 randomised trial. Lancet, 354(9181):795-802.

Kharsany, A.B. \& Karim, Q.A. (2016): HIV infection and AIDS in sub-saharan Africa: Current status, challenges and opportunities. Open AIDS J., 10:34-48.

Kurapati, K.R.V., Atluri, V.S., Samikkannu, T., Garcia, G. \& Nair, M.P. (2016): Natural products as anti-HIV agents androle in HIV-associated neurocognitive disorders (hand): A brief overview. Front. Microbiol., 6:1444

Lucera, M.B., Tilton, C.A., Mao, H., Dobrowolski, C., Tabler, C.O., Haqqani, A.A., Karn, J. \& Tilton, J.C. (2014): The histone deacetylase inhibitor vorinostat (SAHA) increases the susceptibility of uninfected $\mathrm{CD}_{4}+\mathrm{T}$ cells to HIV by increasing the kinetics and eff iciency of postentry viral events. J. Virol., 88:10803-10812.

Maartens, G., Celum, C. \& Lewin, S.R. (2014): HIV infection: Epidemiology, pathogenesis, treatment, and prevention. Lancet, 384:258-271.

Min, B.S., Hattori M, Lee H.K \& Kim Y.H. (1999): Inhibitory constituents against HIV-1 protease from Agastache rugosa. Arch Pharm., 22(1):75-77.

Sharifi-Rad, J. (2016): Herbal antibiotics: Moving back into the mainstream as an alternative for "superbugs". Cell. Mol. Biol., 62(9):1-2.

Tewtrakul, S. (2007): HIV-1 protease and HIV-1 integrase inhibitory substances from Eclipta prostrata. Phytother. Res., 21(11):1092-1095.

WHO. (1989): In vitro screening of traditional medicines for antiHIV activity: Memorandum from a WHO meeting. Bull. World Health Organ, 87:613-618.

WHO. (1989): Report of a Who Informal Consultation on Traditional Medicine and AIDS: In Vitro Screening for AntiHIVActivity; WHO: Geneva, Switzerland. 